\title{
Experimental Study on Mechanical Properties of Freeze-Thaw Damaged Red Sandstone under Combined Dynamic and Static Loading
}

\author{
Song-hua Mei, ${ }^{1,2}$ Xu-li Liang $\mathbb{D}^{3},{ }^{3}$ Lei Wen ${ }^{\mathbb{D}},{ }^{1,4}$ and Zi-long Kou ${ }^{4}$ \\ ${ }^{1}$ Hunan Provincial Key Laboratory of Hydropower Development Key Technology, Changsha City, China \\ ${ }^{2}$ PowerChina Zhongnan Engineering Corporation Limited, Changsha City, China \\ ${ }^{3}$ School of Urban Geology and Engineering, Hebei GEO University, Shijiazhuang City, China \\ ${ }^{4}$ Department of Engineering Mechanics, Shijiazhuang Tiedao University, Shijiazhuang City, China
}

Correspondence should be addressed to Xu-li Liang; 85102594@qq.com and Lei Wen; w10921@126.com

Received 22 March 2021; Revised 21 August 2021; Accepted 15 September 2021; Published 11 November 2021

Academic Editor: Leilei Niu

Copyright $(92021$ Song-hua Mei et al. This is an open access article distributed under the Creative Commons Attribution License, which permits unrestricted use, distribution, and reproduction in any medium, provided the original work is properly cited.

Using the freeze-thaw cycle test chamber, the red sandstone samples are subjected to cyclic freeze-thaw tests. The physical properties, static mechanical properties of freeze-thaw damage rocks, and the compressional wave velocity at specific axial pressure are measured using conventional physical tests and uniaxial compression tests. The mechanical properties of freeze-thaw damage rocks under dynamic and static loading were studied using Hopkinson pressure bar which can exert axial pressure. The studies show that, with the increase of freeze-thaw cycles, the surface layer of the rock sample undergoes spalling phenomenon, the weight gradually decreases, the sample compactness becomes worse, there are microcracks between the cemented particles, and the compressive strength and elastic modulus decrease. Under the static loading, the longitudinal wave velocity of freeze-thaw damaged samples change significantly compared with that of samples without freeze-thaw. The freeze-thaw damage degree, axial pressure, and strain rate are coupled with each other, which together affect the dynamic mechanical properties of samples, and make the variation of mechanical parameters, such as dynamic peak strength and dynamic elastic modulus of rock. The combined action of freeze-thaw damage and axial pressure weakens the strain rate effect of samples, but when the incident wave of SHPB test is same, the dynamic strength and elastic modulus of freeze-thaw damaged samples are reduced compared with those without freeze-thaw. Combining with strain equivalence principle, the constitutive relation of freeze-thaw damage of red sandstone under dynamic and static combined loading can reflect the influence of coupling damage of axial pressure and freeze-thaw, dynamic impact parameters, and other factors, which are in good agreement with the test results.

\section{Introduction}

The rock experienced seasonal and diurnal temperature changes and repeated frost heaving, which result in freezethaw damage and mechanical property changes [1]. Under the normal circumstances, the rock itself has static stress action, and when subjected to dynamic load action such as blasting, earthquake, and mechanical vibration, a dynamic and static combined loading mode will occur. The combined dynamic and static loading failure mode for freeze-thaw damage rock is common in cold region engineering. Therefore, the study on the mechanical properties of freeze- thaw damaged rocks under the combination of dynamic and static loading has important theoretical guiding significance and practical engineering application value.

A series of achievements have been made in the study of freeze-thaw rock, and the microscopic analysis has been carried out by combining CT scanning, nuclear magnetic resonance, scanning electron microscope, and other modern methods. Geng-she et al. [2] proposed the development direction of multiscale damage identification and evaluation mechanism of freeze-thaw rock mass and preliminarily discussed the microfine-macrocross-scale cognitive thinking of freeze-thaw induced rock mass damage. Liu et al. [3] 
investigated the damage evolution law of rock mass with different macroscopic and microscopic defects under freezethaw cycles using nuclear magnetic resonance technology. Wen et al. [4] studied the change rules of physical and mechanical properties of rocks after freeze-thaw cycles at varying temperatures and preliminarily discussed the engineering application of the freeze-thaw rock test results. İsmailince [5] studied the static mechanical parameters of pyroclastic rocks after freeze-thaw and then established static uniaxial compressive strength prediction model and analyzed the microscope images of freeze-thaw rocks. Fener et al. [6] analyzed the porosity, uniaxial compressive strength, and tensile strength of the rock and studied the polarizing microscope images. Khanlari et al. [7] analyzed the physical and static mechanical properties of red sandstone after freeze-thaw. Park et al. [8] analyzed the freezethaw damage of rocks qualitatively and quantitatively from the microscopic perspective by using electron microscope and CT scanning methods. However, these achievements are all related studies under static load of freeze-thaw rocks, and experimental studies on dynamic loading of freeze-thaw rocks have only appeared gradually in recent years. Wang et al. [9] studied the dynamic mechanical properties of rock samples before and after freeze-thaw by using split Hopkinson pressure bar (SHPB) equipment with a diameter of $100 \mathrm{~mm}$, analyzed the changes of physical, static, and dynamic mechanical properties of rock samples, fitted the stress-strain curves measured in the experiment, and used scanning electron microscopy to understand the structural changes of the sample. Zhou et al. [10] studied the changes of saturated porosity of rocks with different freeze-thaw cycles and the dynamic mechanical properties of rocks using the SHPB system and conducted detailed studies using nuclear magnetic resonance technology. Lei et al. [11] carried out freeze-thaw experiments on granite porphyry samples and used one-dimensional SHPB equipment for impact loading to study the changes of physical and mechanical properties of different freeze-thaw rocks; combined with numerical simulation software, the dynamic strength of rock samples with different freeze-thaw cycles under the same strain rate was analyzed. At present, there are still few studies on dynamic mechanical properties of rock under freeze-thaw, especially the experimental studies on coupled static-dynamic loading of freeze-thaw rock are even few. At present, new progresses has been made in rock damage studies [12]. Zhang et al. [13] studied the influence law of the coupling effect of freeze-thaw and static load on the total damage, and the damage constitutive model of freeze-thaw rock under static load is established. Based on the generalized HoekBrown criterion and the theory of continuous damage mechanics, Xu et al. [14] introduced the coupled damage factor of freeze-thaw and load and established the elasticplastic damage mode to characterize the weakening effect of coupling damage on the strength parameters and elastic modulus of rock mass. Lu et al. [15] established the damage evolution equation of freeze-thaw sandstone under load based on the Lemaitre strain equivalent principle and continuum damage mechanics theory. However, these are rock damage studies under the coupling influence of freeze- thaw and static load, and there are few studies on damage evolution of rock under the coupling effects of freeze-thaw and dynamic load.

In this paper, the red sandstone samples with different freeze-thaw cycles are taken as the research object which undergo uniaxial compression tests and electron microscope scanning tests. using the SHPB equipment which can apply axial pressure, coupled static-dynamic loading tests of rocks with different degrees of freeze-thaw damage are carried out; the dynamic mechanical properties of rock under the coupling effects of static load, freeze-thaw damage, and strain rate are studied, and the constitutive relation including axial pressure and freeze-thaw coupling damage are discussed.

\section{Static Mechanical Properties of Freeze-Thaw Damaged Red Sandstone}

2.1. Sample Processing and Experimental Procedures. The freeze-thaw cycles, static tests, and SHPB tests of the sample were carried out in accordance with relevant specifications $[16,17]$. The size of the samples is $50 \mathrm{~mm} \times 100 \mathrm{~mm}$ and $50 \mathrm{~mm} \times 50 \mathrm{~mm}$ cylinders, respectively, of which the $50 \mathrm{~mm} \times 100 \mathrm{~mm}$ samples are used for uniaxial compression experiment and the $50 \mathrm{~mm} \times 50 \mathrm{~mm}$ samples are used for coupled static-dynamic loading experiment. Ultrasonic testings are carried out on all samples, sample selections are completed, and longitudinal wave velocity values of the samples are recorded. The red sandstone sample is shown in Figure 1. According to different freeze-thaw cycles, the rock samples are divided into 4 groups, every 15 samples are in one group (including 3 samples with a height-diameter ratio of $1: 2$ and 12 samples with a height-diameter ratio of $1: 1$ ). The test steps are as follows.

2.1.1. Physical Index Testing of the Sample. The mass, dimension, and compressional wave velocity of the rock samples are measured after drying them with electrothermal blowing dry box; after filling the samples with vacuum water filling equipment, the mass of the saturated rock samples is measured, and the dry density and saturated water absorption rate of the samples are calculated.

2.1.2. Cyclic Freeze-Thaw Test of Samples. The second, third, and fourth groups of rock samples are put into the automatic freeze-thaw box for 10, 20, and 30 freeze-thaw cycles, respectively, in which the temperature range is $-20^{\circ} \mathrm{C} \sim 20^{\circ} \mathrm{C}$, and both the freeze and thaw times are 4 hours as a cycle. The mass, volume, and compressional wave velocity of the samples are measured after every 10 freeze-thaw cycles.

\subsubsection{Uniaxial Compression of Freeze-Thaw Damaged} Samples. The samples after the freeze-thaw cycles (the freeze-thaw times of samples for group 1-4 are 0,10,20, and 30 , respectively) are scanned by electron microscope and carried out uniaxial compression test. In the process of 


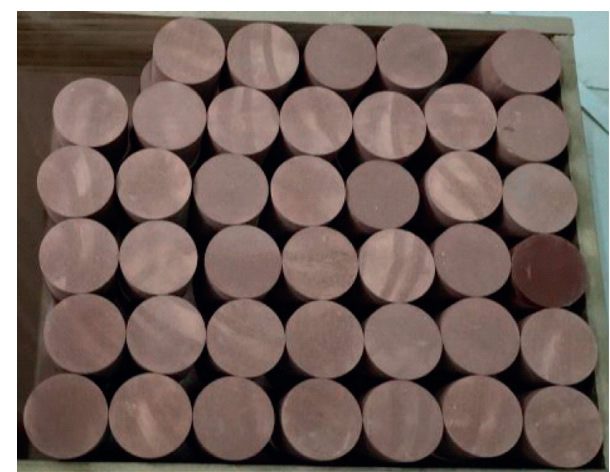

Figure 1: Red sandstone samples.

uniaxial compression, the longitudinal wave velocity of a sample is collected when the axial pressure reached $5 \mathrm{MPa}$.

\subsubsection{Dynamic and Static Combined Loading Experiment of} Freeze-Thaw Damaged Samples. The SHPB equipment which could apply axial pressure is used to carry out dynamic and static combined loading tests on samples with different freeze-thaw cycles. The axial pressure values are $0 \mathrm{MPa}$ and $5 \mathrm{MPa}$, respectively, and the peak values of incident stress waves are $68.9 \mathrm{MPa}, 83.6 \mathrm{MPa}$, and $116.3 \mathrm{MPa}$, respectively (the air gun pressures are finely adjusted around $0.07 \mathrm{MPa}, 0.1 \mathrm{MPa}$, and $0.14 \mathrm{MPa}$ ). The shapes of incident wave, reflected wave, and transmitted wave are obtained, and the stress-strain relationship under the combined load of dynamic and static could be obtained.

\subsection{Freeze-Thaw Damage Pattern and Physical and Mechanical Indexes}

2.2.1. Physical Index. The average dry density and saturated water absorption rate of the samples are calculated by measuring the dry mass and saturated water mass of the rock sample, and the wave velocity of the dry samples is measured, as shown in Table 1.

After freeze-thaw cycles, both the rock density and wave velocity decrease, while the water absorption rate increases, which are the common characteristics of rock damage after freeze-thaw. The longitudinal wave velocity can be used to represent the damage variable of the sample, as shown in the following equation $[18,19]$ :

$$
D=1-\left(\frac{\overline{V_{P}}}{V_{P}}\right)^{2},
$$

where $V_{P}$ and $\overline{V_{P}}$ are the longitudinal wave velocities of rock samples before and after freeze-thaw.

The wave velocity of the sample in Table 1 is substituted into equation (1) to obtain the damage variable $D_{n}$ of the sample with different freeze-thaw cycles. After freeze-thaw for 10 cycles, 20 cycles, and 30 cycles, the damage variables of the sample are $0.21,0.36$, and 0.41 , respectively. The variable of freeze-thaw damage in the first 10 cycles increases the most, with the change value reaching 0.21 . After that, the total damage variable of the next 20 freeze-thaw cycles is
0.20 , indicating that the first 10 cycles of freeze-thaw cause the great damage to the sample, and the damage growth is slightly gentle after that. In general, the antifreeze-thaw and weathering ability of red sandstone are poor, and less freezethaw cycles will cause great damage.

2.2.2. Freeze-Thaw Damage Pattern. During the freezingthawing cycles, no macroscopic cracks were found in the samples, all of which are surface particles spalling, and the surface shedding becomes more obvious with the increase of the freeze-thaw cycles, as shown in Figure 2.

With the increase of freezing-thawing cycles, the weight of single sample decreases gradually, which is mainly caused by the shedding of particles on the rock surface. The weight of saturated and dried red sandstone gradually decreases, and the overall trend of decline is basically consistent, but the degree of change is slightly different, as shown in Figure 3. This is due to the change of the penetration degree of the crack after different freeze-thaw cycles, which results in the change of the water content of the sample.

The GeminiSEM 300 electron microscope scanner is used to obtain the microscopic images of the same sample that are magnified 300 times after $0,10,20$, and 30 freezethaw cycles, as shown in Figure 4.

With the increase of freeze-thaw cycles, the fine morphology of red sandstone changed greatly. The particle of the rock sample without freeze-thaw is relatively complete, the density of material in plane is higher, the internal cracks are few, the cracks between the particles are closed, and the cement is firm. After 10 freeze-thaw cycles, the plane compactness has become significantly worse, granular material appears on the surface of particles, microcracks appear between the cemented particles, and the degree of cementation is weakened. During the 20 and 30 freeze-thaw cycles, more cracks are formed between the particles, the surface roughness of the particles increases gradually, the clastic materials increase significantly, and the width of the cracks also increases gradually. The results of scanning electron microscope show that with the increase of freezing-thawing cycles, particle cementation materials lose, particle integrity reduces, internal porosity increases, the width of the microcracks increase, and the degree of cementation between particles decreases.

2.2.3. Static Mechanical Properties. The uniaxial compression test is carried out on a hydraulic servo rigidity test machine. In the uniaxial compression tests, the samples are loaded at the rate of $0.5 \mathrm{MPa} / \mathrm{s}$ until failure. A wave velocity measuring device capable of applying pressure is installed to measure the sample's wave velocity when the stress value reaches $5 \mathrm{MPa}$. The schematic diagram of wave velocity test during uniaxial loading is shown in Figure 5. The rock sonic meter (type: HS-YS4A) is used to test the longitudinal wave velocity before and after the freeze-thaw cycles of the sample and the wave velocity during uniaxial loading. The rock sonic meter is composed of microcontroller, high-voltage excitation, signal acquisition, multicomponent piezoelectric transducer, and other modules, with wide frequency band 
TABLe 1: Physical indexes of samples with different freeze and thaw cycles.

\begin{tabular}{lccc}
\hline Cycle of freeze and thaw & Dry density $\left(\mathrm{g} / \mathrm{cm}^{3}\right)$ & Wave velocity of dry samples $(\mathrm{m} / \mathrm{s})$ & Saturated water absorption rate $(\%)$ \\
\hline 0 & 2.53 & 3248 & 2.53 \\
10 & 2.52 & 2889 & 2.55 \\
20 & 2.50 & 2598 & 2.87 \\
30 & 2.48 & 2494 & 3.03 \\
\hline
\end{tabular}

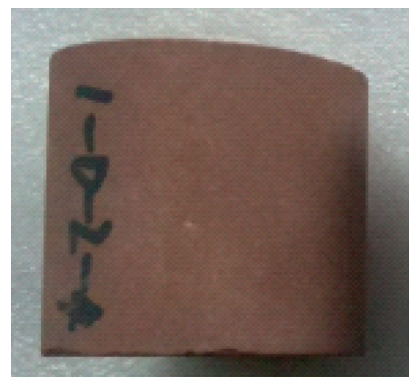

(a)

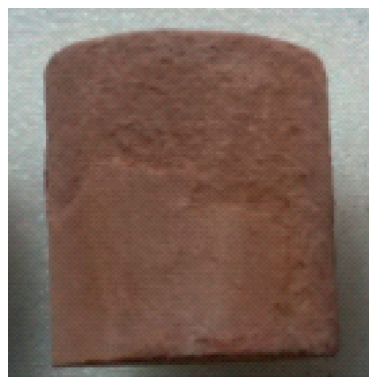

(b)

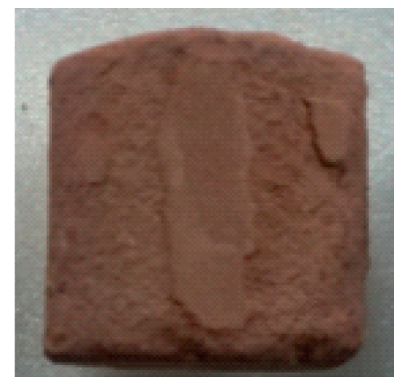

(c)

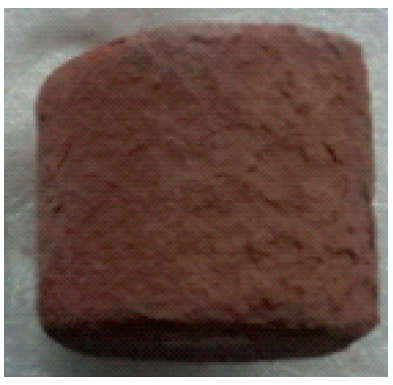

(d)

Figure 2: Freeze-thaw damage pattern of rock sample. (a) 0 cycle, (b) 10 cycles, (c) 20 cycles, and (d) 30 cycles.

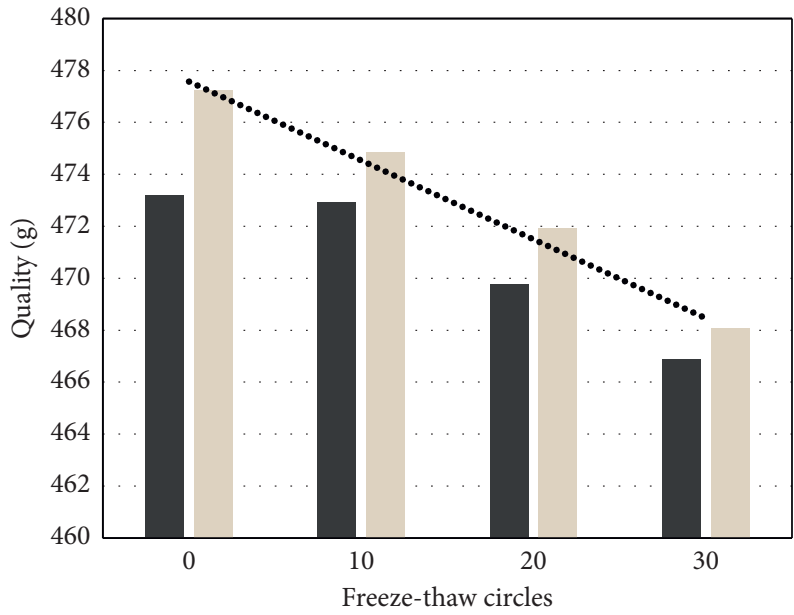

Dried sample

- Saturated sample

FIGURE 3: Histogram of relation between average weight of rock samples and freeze-thaw cycles.

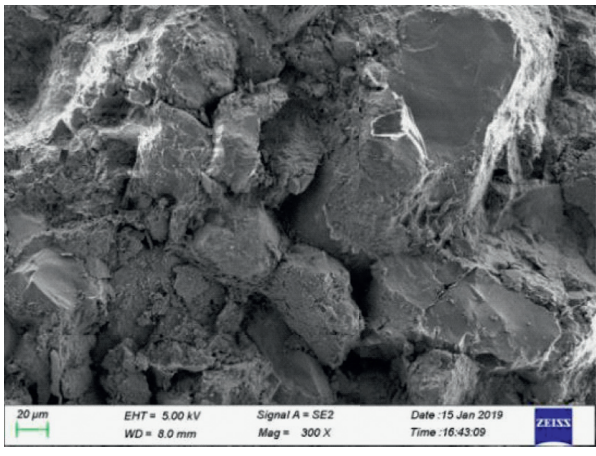

(a)

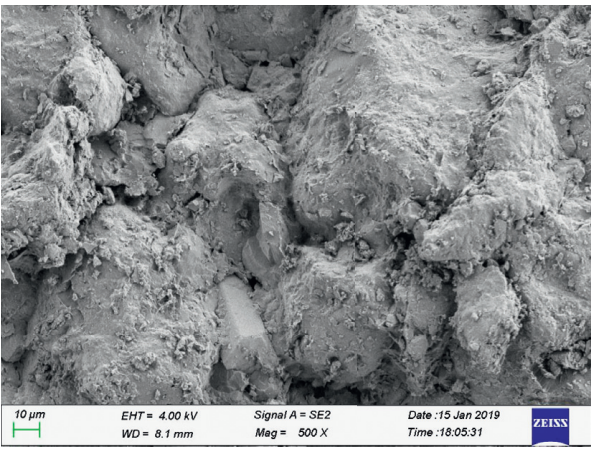

(b)

Figure 4: Continued. 


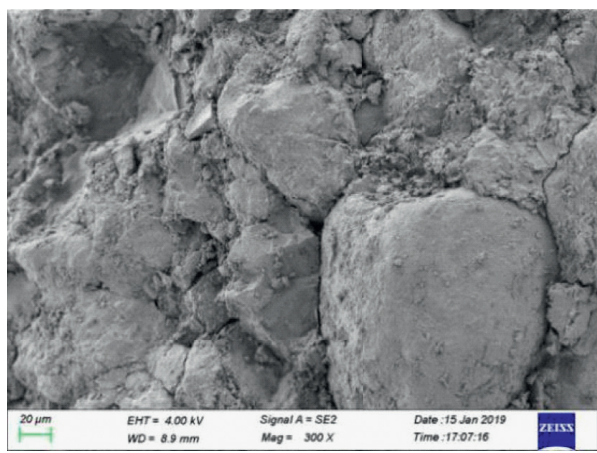

(c)

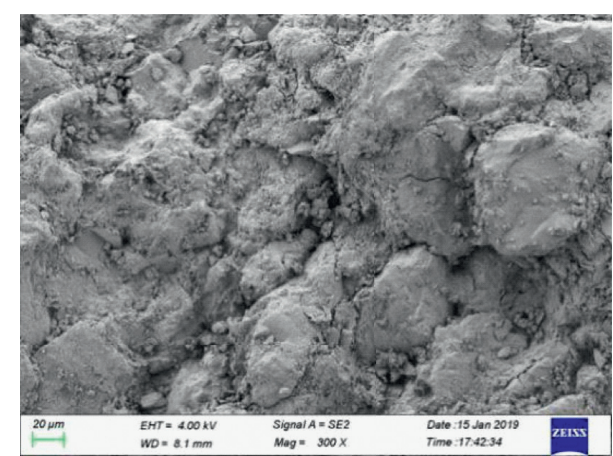

(d)

FIGURE 4: Scanning electron microscope images of rock samples before and after freeze-thaw (×300). (a) 0 cycles, (b) 10 cycles, (c) 20 cycles, and (d) 30 cycles.

and high sensitivity, whose transducer can withstand the static pressure of uniaxial experiment. The uniaxial compression failure of the samples with different freeze-thaw cycles is shown in Figure 6, and the samples before and after freeze-thaw show the shear failure mode of single or double inclined plane. Typical stress-strain curves of red sandstone samples with different freeze-thaw cycles are shown in Figure 7. Uniaxial compressive strengths of red sandstone samples with $0,10,20$, and 30 freeze-thaw cycles are 30.1 MPa, 15.0 MPa, 12.1 $\mathrm{MPa}$ and 11.0 MPa, respectively.

Both the freeze-thaw samples without freeze-thaw and freeze-thaw samples after ten cycles show typical brittle failure characteristics. The postpeak curves of the samples are more gentle after more freeze-thaw cycles, which show certain ductility failure characteristics of samples. The stressstrain curves of different freeze-thaw cycles are divided into four stages, namely, compaction stage, elastic stage, crack development stage, and failure stage. With the increase of freeze-thaw cycles, the compaction stage is significantly extended, especially the compaction stage of the rock samples after ten freeze-thaw cycles, indicating that the first ten freeze-thaw cycles lead to the significant development of microcracks in the samples. According to the classification standard of rock hardness, the samples before freeze-thaw are relatively hard rocks, which turn to soft rocks after ten freeze-thaw cycles. During 20-30 freeze-thaw cycles, the samples are soft rocks.

In this paper, the decay function model proposed by Mutluturk et al. [20] is adopted to represent the strength decay of red sandstone samples. In this model, the decay rate of rocks is represented by two parameters, decay constant, and half-life, and the function model is expressed as

$$
I_{N}=I_{0} e^{-\lambda N},
$$

where $e^{-\lambda N}$ is the decay coefficient; $\lambda$ is the decay constant; $N$ is the cycle number of freeze-thaw; $I_{0}$ represents the initial integrity of the rock; $I_{\mathrm{N}}$ represents the integrity of rock after $\mathrm{N}$ cycles of freeze and thaw.

The half-life $N_{1 / 2}$ is the number of freeze-thaw cycles when an index of the rock drops to half of the initial value, and the half-life $N_{1 / 2}$ is expressed as

$$
N_{1 / 2}=\frac{\ln 2}{(\lambda \approx 0.693 / \lambda)}
$$

According to formula (2), the relation curve between the number of freeze-thaw cycles and the uniaxial compressive strength can be fitted by MATLAB software, as shown in Figure 8. The fitting relation is $\sigma=28.39 e^{-0.04335 N}$, where the decay constant $\lambda$ is 0.04335 , and the half-life $N_{1 / 2}$ is 16 . The root-mean-square error $R^{2}$ of this fitting is 0.90 , indicating the fitting effect is good.

According to the principle of rock decay function model, the decay constant $\lambda$ and the half-life $N_{1 / 2}$ are the integrity loss parameters under the freeze-thaw cycle of rock. The decay constant is inversely proportional to the half-life, and the larger the half-life is, the smaller the decay constant is, indicating the stronger the rock's frost and thawing resistance is.

\subsubsection{Static Load and Freeze-Thaw Coupling Damage.} During uniaxial compression, the longitudinal wave velocity of the primary sample is collected at the axial pressure of $5 \mathrm{MPa}$, and the wave velocities are $3279 \mathrm{~m} / \mathrm{s}, 2952 \mathrm{~m} / \mathrm{s}$, $2666 \mathrm{~m} / \mathrm{s}$, and $2577 \mathrm{~m} / \mathrm{s}$ for the $0,10,20$, and 30 freeze-thaw cycles, respectively. According to formula (2), damage variables of freeze-thaw rock under axial pressure of $5 \mathrm{MPa}$ are obtained, as shown in Table 2 .

When the axial pressure is $5 \mathrm{MPa}$, with the increase of the freeze-thaw cycles, the damage variable under the action of freeze-thaw and axial pressure gradually increases, the damage variable of rock without freeze-thaw under axial pressure is negative, mainly because the sample is in the elastic stage under the axial pressure of $5 \mathrm{MPa}$, and the microcracks do not form and expand on a large scale. On the contrary, microcracks with specific occurrence may close [21], making the damage variable of the sample negative. Under the axial pressure of $5 \mathrm{MPa}$ after freeze-thaw cycles, the samples are also in the elastic stage, and the microcracks tend to close. The axial pressure reduces the damage variables, but the freeze-thaw damage of the samples is relatively serious, so that the damage variables under the coupling of freeze-thaw and axial pressure are all positive and increase significantly with the increase of the degree of freeze-thaw 


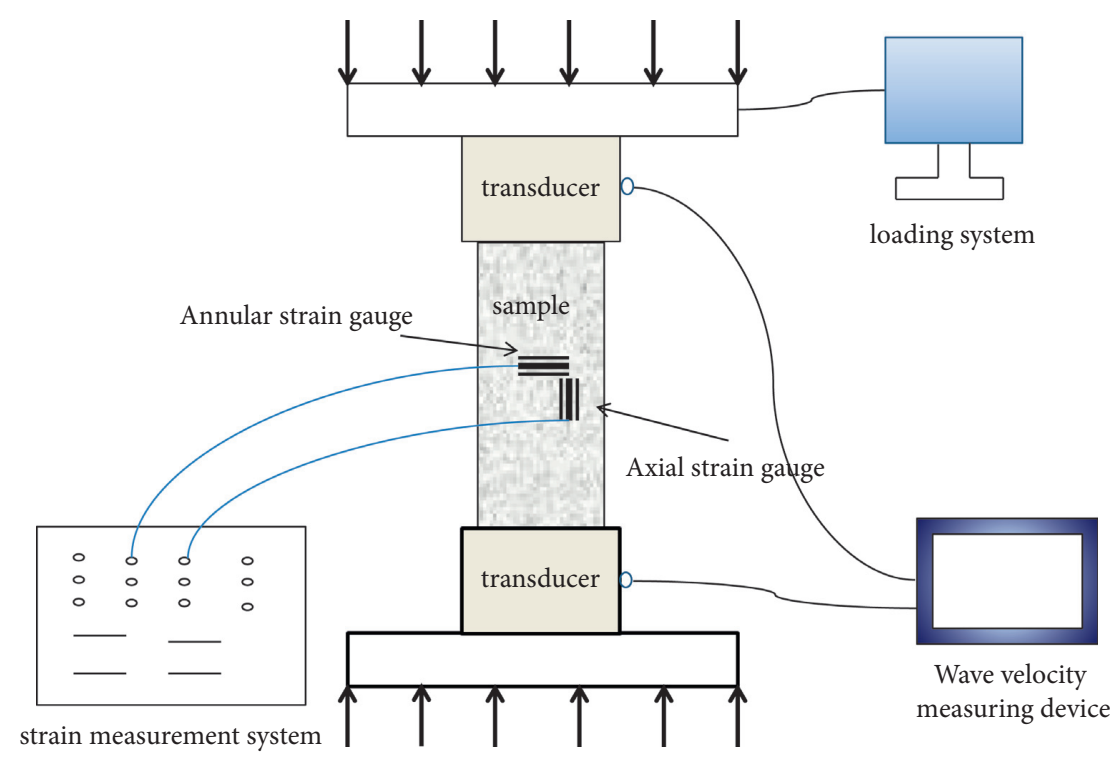

FIGURE 5: Longitudinal wave velocity test during loading.

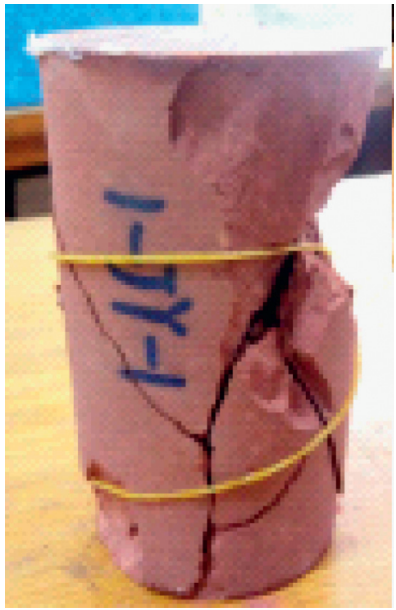

(a)

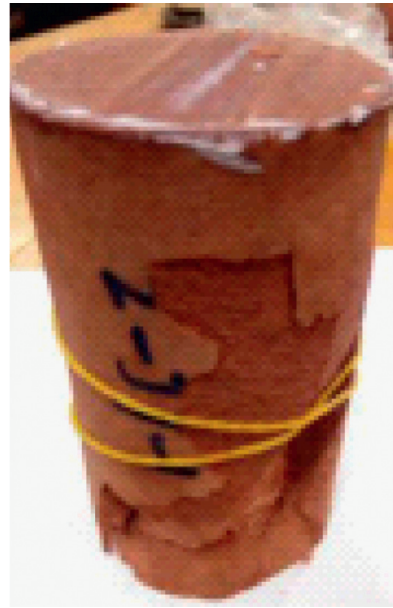

(b)

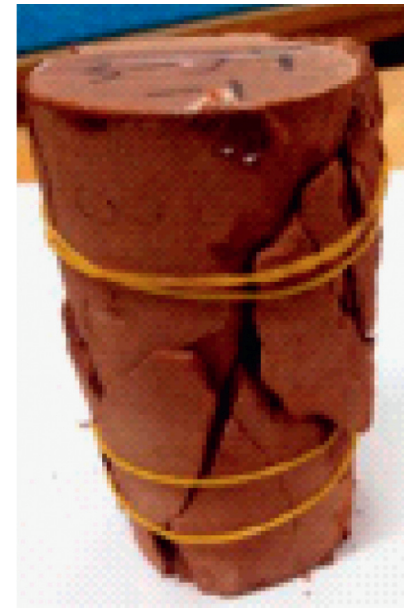

(c)

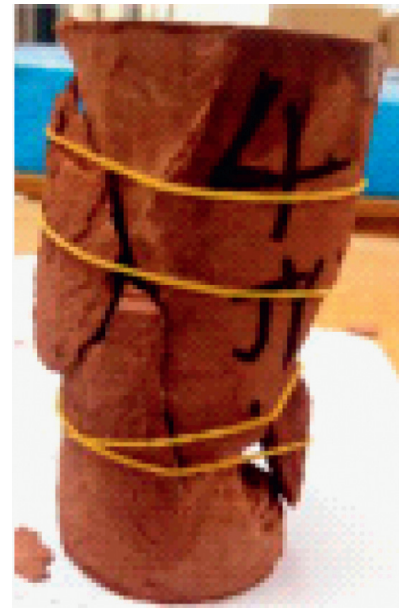

(d)

Figure 6: Failure modes of uniaxial compression for samples with different freeze-thaw cycles. (a) 0 cycle, (b) 10 cycles, (c) 20 cycles, and (d) 30 cycles.

damage. This paper only discusses the results of freeze and thaw within 30 cycles, according to the development trend of rock freeze-thaw damage; if the freeze-thaw cycles exceed a certain range, the stress of $5 \mathrm{MPa}$ will make the sample in the crack development stage, at which time the axial pressure will increase the damage variable.

\section{Dynamic and Static Combined Loading Experiment of Freeze-Thaw Damaged Red Sandstone}

The SHPB equipment, which can exert axial pressure, is used to carry out the combined loading experiment of freeze-thaw damaged red sandstone. The experimental principle of the SHPB equipment is mainly to detect the incident wave, reflected wave, and transmitted wave in the incident bar and the transmission bar through the strain gauge and to derive the stress, strain, and strain rate of the sample by applying the stress wave theory, so as to obtain the stress-strain relationship. The SHPB equipment is shown in Figure 9. The incident rod, transmission rod, and absorption rod diameter of the SHPB equipment is $50 \mathrm{~mm}$, and the lengths are $3000 \mathrm{~mm}, 2000 \mathrm{~mm}, 1000 \mathrm{~mm}$, respectively. It is made of $40 \mathrm{Cr}$ alloy steel material, with density $7810 \mathrm{~kg} / \mathrm{m}^{3}$, longitudinal wave velocity $5410 \mathrm{~m} / \mathrm{s}$, and elastic modulus $210 \mathrm{GPa}$.

A wave shaper is placed at the end of the incident bar, and the wave is half sine wave, which can effectively eliminate the wave dispersion. The typical incident wave (signal-i), transmitted wave (signal-t), and reflected wave (signal-r) obtained directly by the test are shown in Figure 10. In addition, the superimposed waveform of incident wave and reflected wave (signal- $(i+r)$ ) is in good agreement with the transmitted wave. 


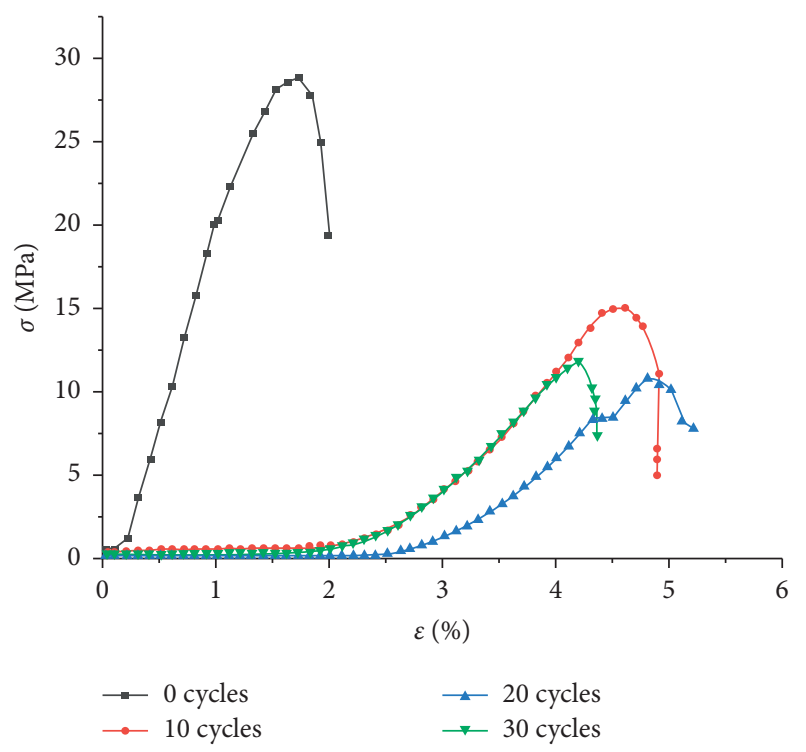

Figure 7: Typical stress-strain curves of samples with different freeze-thaw cycles.

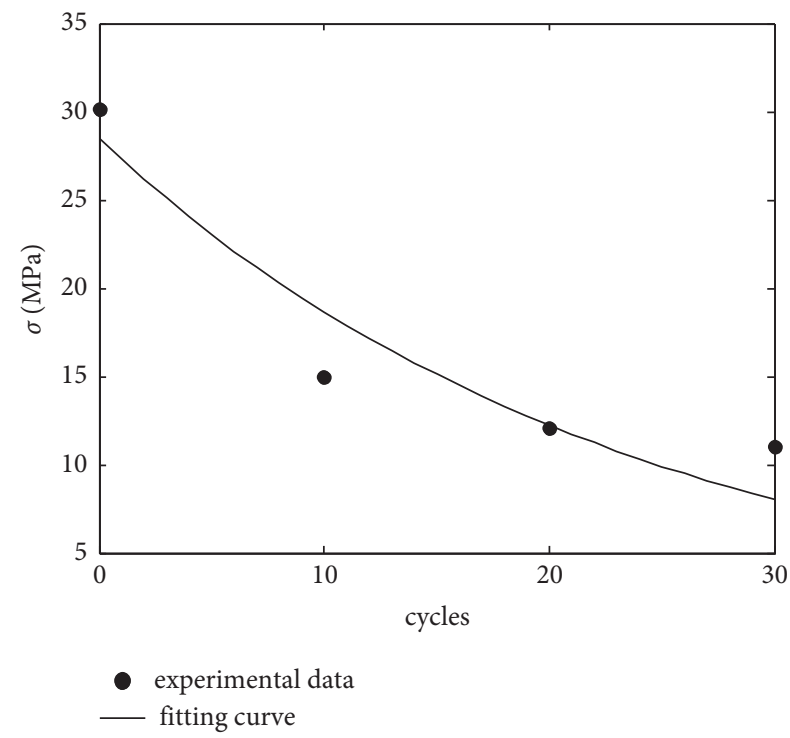

FIGURE 8: Relation curve between uniaxial compressive strength and freeze-thaw coefficient.

TABLe 2: Damage variable value when axial pressure is $5 \mathrm{MPa}$.

\begin{tabular}{lcccc}
\hline Freeze-thaw cycle & 0 & 10 & 20 & 30 \\
Damage variable & -0.02 & 0.17 & 0.34 & 0.37 \\
\hline
\end{tabular}

When the emission pressure is $0.07 \mathrm{MPa}$, no macroscopic cracks appeared on the samples without freeze-thaw, but all other samples show macroscopic cracks. Taking the results of freeze-thaw for 10 cycles and the axial pressure of $5 \mathrm{MPa}$ as an example, the failure modes of red sandstone under different impact pressures are shown in Figure 11.

The fractures spread along the axial direction and all the rock samples show tensile failure mode. When the emission pressure is $0.07 \mathrm{MPa}$, a penetrating fracture is generated in

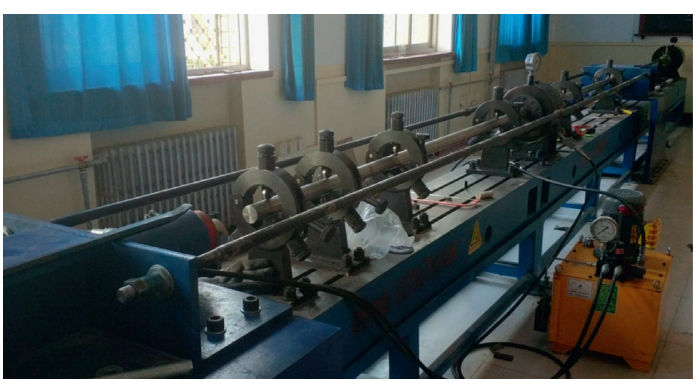

Figure 9: SHPB test equipment.

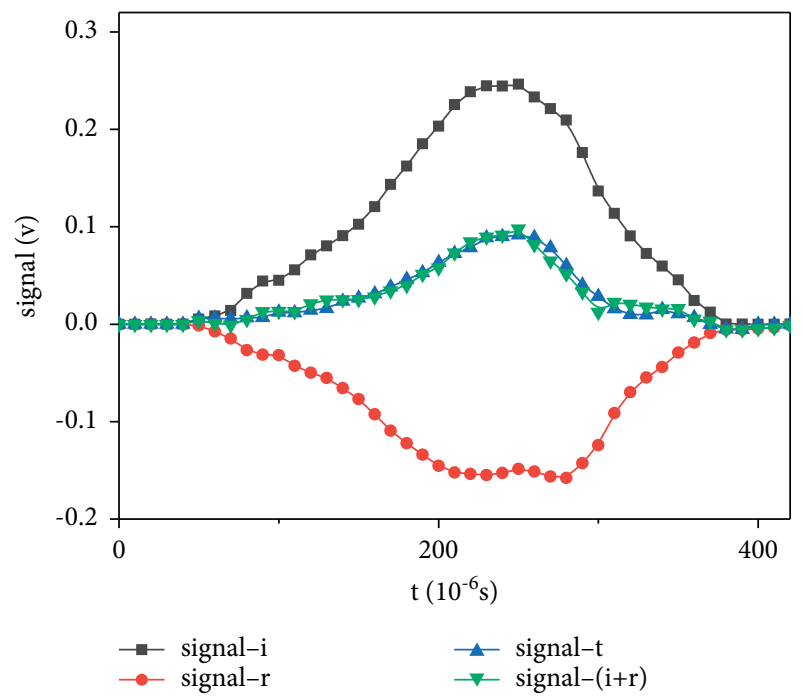

Figure 10: Typical incident, reflected, and transmitted waves.

the rock sample, and the sample reaches critical failure. With the increase of impact pressure, the number of fractures increases significantly. The failure of the sample without freeze-thaw is accompanied by a tremendous sound, the surface of the fragments is smooth, the fine particles are fewer, and the particles are hard, while the surface of the fragments of the rock after freeze-thaw is rough, and some of them have obvious cracks on the surface, with many fine particles and soft particles.

Figure 12 shows the stress-strain curves of different freeze-thaw damaged samples when axial pressures are $0 \mathrm{MPa}$ and $5 \mathrm{MPa}$ and emission pressures are $0.07 \mathrm{MPa}$ and $0.1 \mathrm{MPa}$.

The dynamic peak strength of red sandstone is closely related to freeze-thaw damage and axial stress. The dynamic stress-strain curves of the samples under the combined dynamic and static loading have no obvious compaction stage, which is mainly caused by the late closure of the microcracks in the samples under the impact loading and the large inertia of the rock crystals. With the increase of freezethaw damage, the peak stress of red sandstone decreases gradually, deformation modulus decreases gradually, peak strain increases, and the ductility increases after the rock is damaged by freeze-thaw. The freeze-thaw cycles cause serious damage to the internal structure of red sandstone and reduce its resistance to load. The axial pressure and impact strength have great influence on the peak and postpeak 


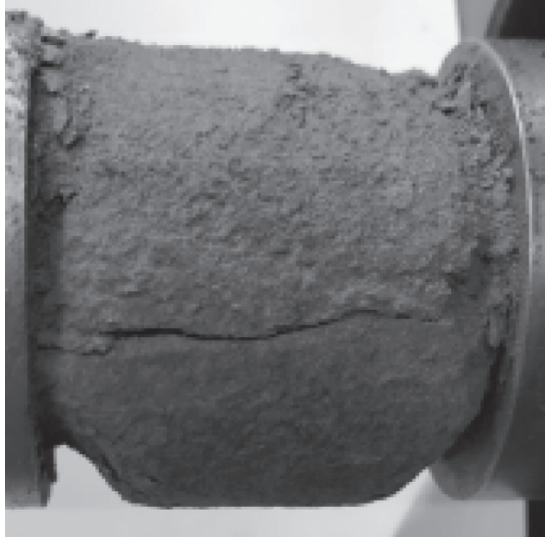

(a)

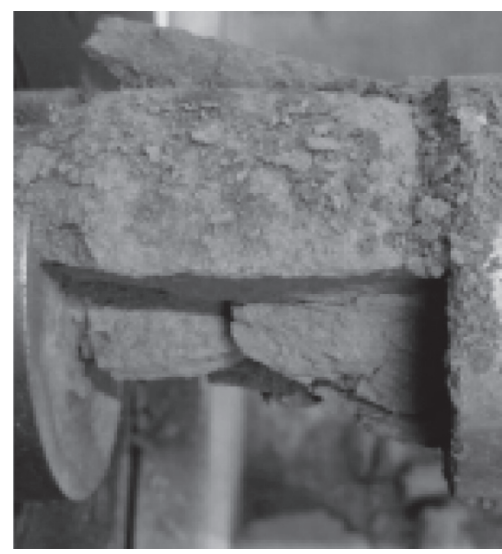

(b)

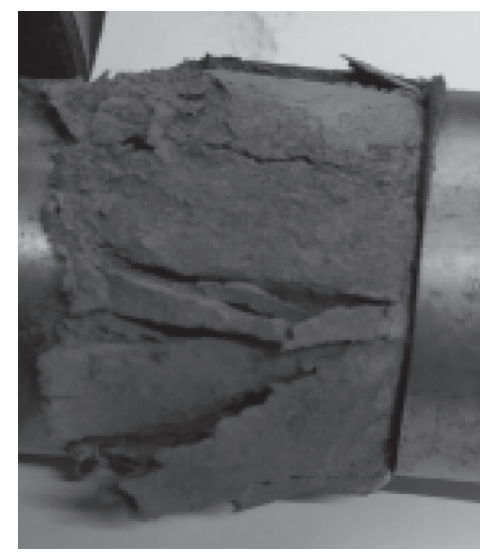

(c)

Figure 11: Failure modes of rock samples under 10 cycles of freeze-thaw, axial pressures of $5 \mathrm{MPa}$, and different emission pressures. (a) $0.07 \mathrm{MPa}$, (b) $0.1 \mathrm{MPa}$, and (c) $0.14 \mathrm{MPa}$.
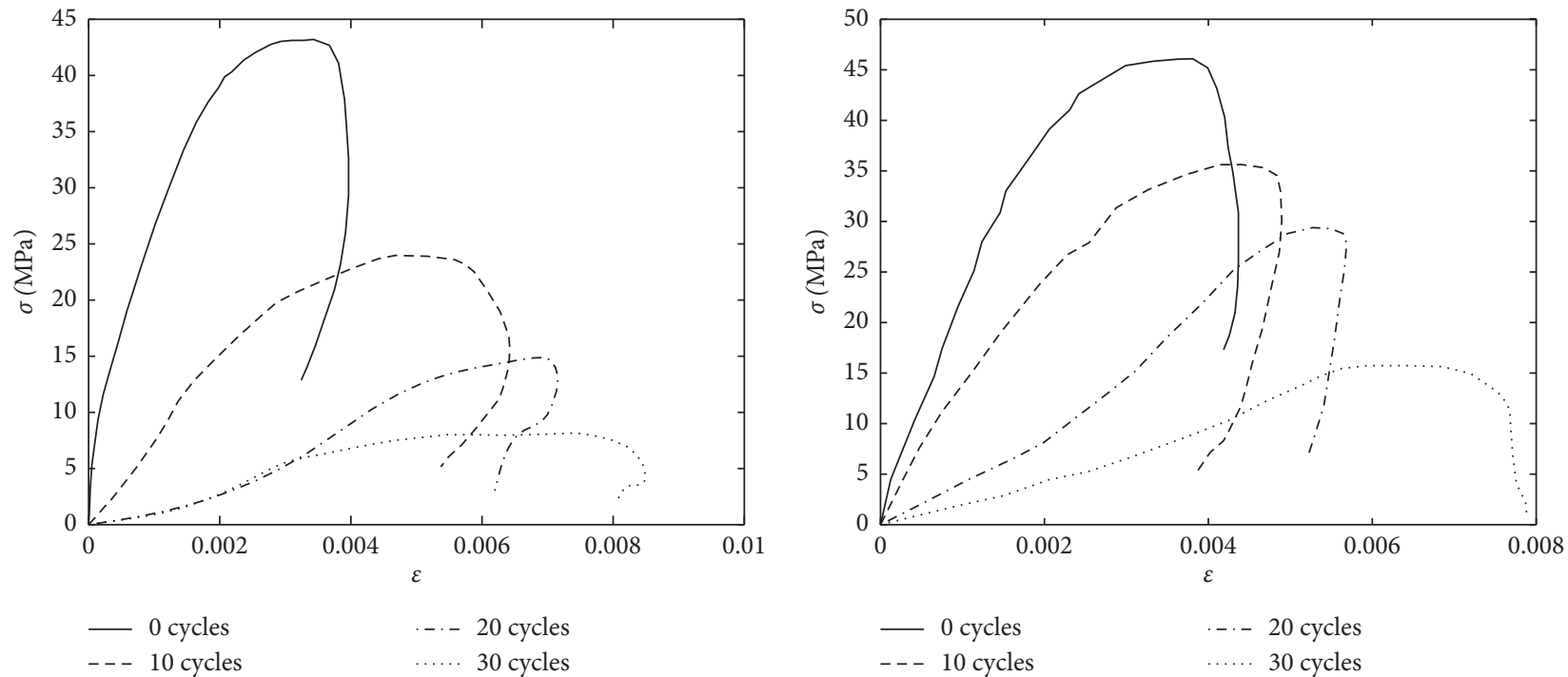

(a)

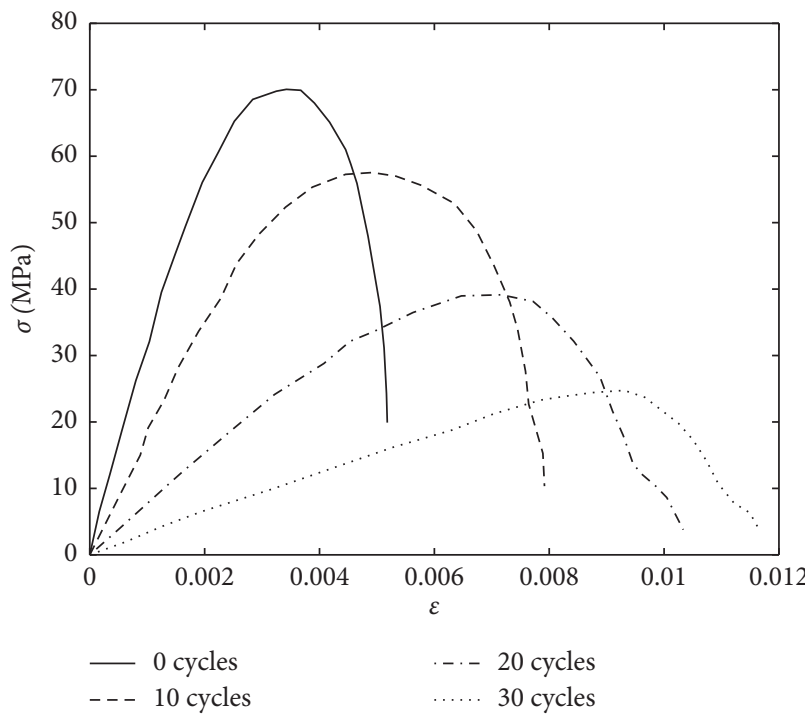

(c)

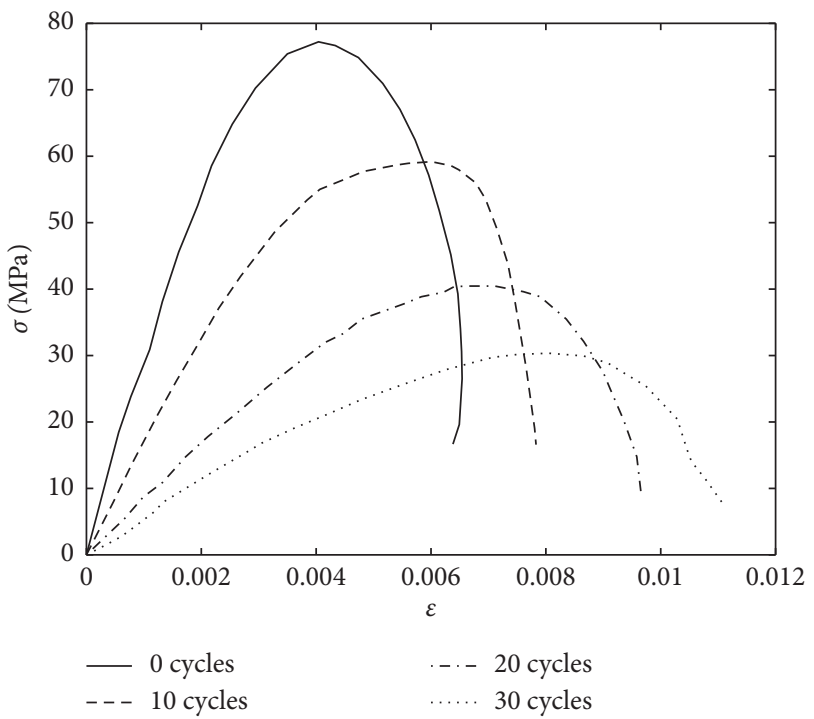

(d)

Figure 12: Stress-strain curves of different freeze-thaw damaged samples. (a) Axial pressure of $0 \mathrm{MPa}$ and (b) axial pressure of $5 \mathrm{MPa}$ and emission pressure of $0.07 \mathrm{MPa}$. (c) Axial pressure of $0 \mathrm{MPa}$ and (d) axial pressure of $5 \mathrm{MPa}$ and emission pressure of $0.14 \mathrm{MPa}$. 
morphology, and the postpeak (failure stage) curve can be divided into three types, namely, "postpeak plasticity," "stress drop," and "strain rebound." When the axial pressures apply within a certain level [22], the internal microcracks in the rock sample close, the damage variable decreases, and the elastic modulus increases compared with that without axial pressure. Under the axial pressure of $5 \mathrm{MPa}$ applied in this paper, the microcracks of the samples are further closed, and the samples become more compact than without axial pressure. The increase of the wave impedance of the sample leads to the increase of the dynamic strength of the sample under axial pressure when the bullet is fired at the same pressure, which is also proved by relevant reference [23]. Under the same load, the freeze-thaw damage sample has smaller strength and larger plasticity, but the decline amplitude decreases after the axial pressure is applied. This is because the freeze-thaw damage weakens the rock's ability to resist external impact, while a certain degree of axial pressure makes the tiny crack inside the rock close and the structure becomes more compact. Freeze-thaw action increases the crack expansion of rock sample, while axial pressure makes crack close to a certain extent. The two actions are mutually coupled, resulting in new changes in the internal damage of the sample and jointly affecting the mechanical properties of the sample. Both freeze-thaw and unfreeze-thaw rocks have obvious strain rate effect, therefore the degree of freeze-thaw damage, axial pressure, and impact velocity all affect the dynamic mechanical properties of rocks, which makes the changes of mechanical parameters, such as peak strength, peak strain, and elastic modulus of rock subjected to freeze-thaw damage complex.

The change rule between dynamic strength and strain rate of red sandstone with different freeze-thaw cycles is fitted by using the form of exponential function $\sigma=a \cdot e^{b x}$, and the relationship between the dynamic strength of red sandstone and the impact pressure under different freezethaw cycles at the axial pressure of $0 \mathrm{MPa}$ and $5 \mathrm{MPa}$ are shown in Figures 13 and 14. The a and $b$ values of the function $\sigma=a \cdot e^{b x}$ are shown in Table 3.

With the increase of impact velocity, the dynamic strength of rock samples shows strong strain rate effect with a certain number of freeze-thaw cycles. The strength of the rock varies with the emission pressure after freeze-thaw cycles. When the rock samples are applied with the same axial pressure, the value $a$ gradually decreases with the increase of the freeze-thaw cycles, while the value $b$ gradually increases with the increase of freeze-thaw cycles. The strain rate effect of the nonfreeze-thaw rock is the most obvious, and after the freeze-thaw cycles, the strain rate effect of the sample decreases slightly. When the axial pressure is high, the value of $a$ decreases slowly and the value of $b$ increases slowly, indicating that the axial pressure changes the increase degree of strain rate of the sample, so that the strain rate effect of the sample is significantly weakened. The degree of freeze-thaw damage, axial pressure, and impact velocity all affect the dynamic strength of the rock, but in general, the combined effect of freeze-thaw damage and axial pressure reduces the strain rate effect of the sample.

\section{Dynamic Constitutive Relation of Freeze- Thaw Damaged Samples under Axial Pressure}

The degree of freeze-thaw damage, axial pressure, and impact velocity all affect the dynamic mechanical properties of the rock. The damage caused by freeze-thaw and axial pressure is regarded as the initial total damage $D_{0}$ of the sample. The initial total damage $D_{0}$ can be obtained according to Section 2.2 of this paper.

According to the strain equivalence principle proposed by Lemaitre [24] and the generalized strain equivalence principle proposed by Zhang et al. [25], the total rock damage variable after cyclic dynamic impact load and combined dynamic and static load is obtained as follows:

$$
D_{1}=D+D_{0}-D D_{0}
$$

where $D_{1}$ is the total damage variable of rock freeze-thaw and combined dynamic and static load, $D$ is the damage variable caused by dynamic impact load, and $D_{0}$ is the initial damage of rock before dynamic impact load, that is, the total damage of freeze-thaw and preloaded static load for combined dynamic and static load.

The strength of the rock is subject to Weibull statistical distribution, and the rock loading damage factor can be expressed by the following formula [26]:

$$
D=1-\exp \left[-\left(\frac{\varepsilon}{\beta}\right)^{m}\right],
$$

where $M$ is the shape parameter and $\beta$ is the material parameter.

Substituting equation (5) into equation (4), the total damage evolution equation is obtained as follows:

$$
D_{1}=1-\left(1-D_{0}\right) \exp \left[-\left(\frac{\varepsilon}{\beta}\right)^{m}\right] \text {. }
$$

The rock constitutive equation can be expressed as

$$
\sigma=E_{0}\left(1-D_{1}\right) \varepsilon,
$$

where $E_{0}$ is the dynamic elastic modulus of the intact sample.

Substitute equation (6) into equation (7) and get

$$
\sigma=E_{0} \varepsilon\left(1-D_{0}\right) \exp \left[-\left(\frac{\varepsilon}{\beta}\right)^{m}\right] .
$$

Equation (8) is the dynamic constitutive equation of freeze-thaw damaged samples under axial pressure.

Combined with the characteristics of dynamic stress-strain curve, equation (8) satisfies the following four conditions:

(1) When $\varepsilon=0, \sigma=0$

(2) When $\varepsilon=0, \mathrm{~d} \sigma / \mathrm{d} \varepsilon=E$

(3) When $\varepsilon=\varepsilon_{\max }, \sigma=\sigma_{\max }$

(4) When $\varepsilon=\varepsilon_{\text {max }}, \mathrm{d} \sigma / \mathrm{d} \varepsilon=0$

Since there is no compaction stage for impact stressstrain curve basically, therefore the condition (2) conforms to the characteristic of the dynamic stress-strain curve. 


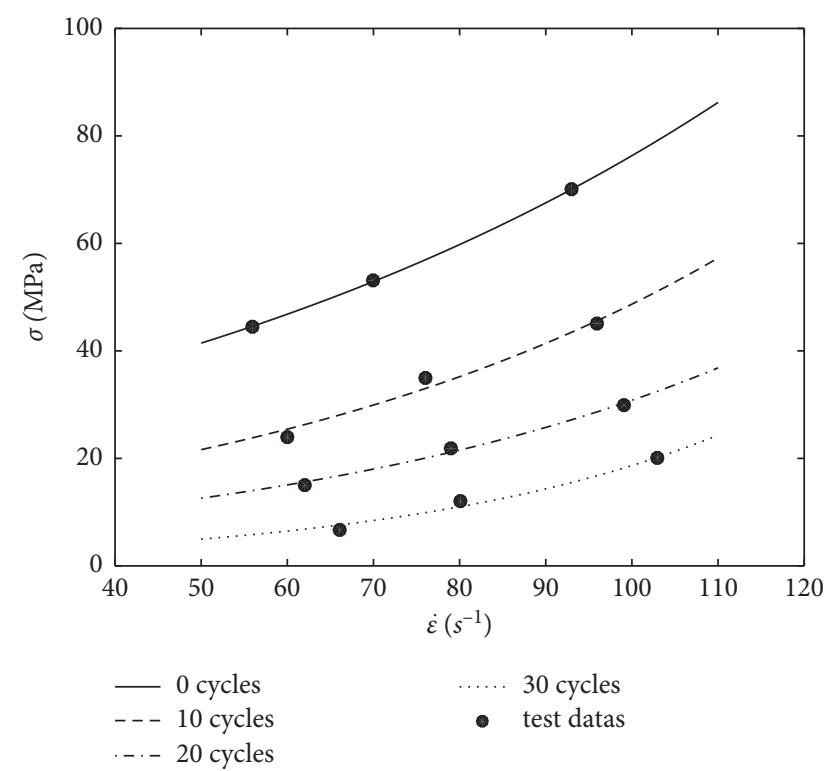

Figure 13: Relationship between strain rate and strength of samples with different freeze-thaw cycles under the axial pressure of $0 \mathrm{MPa}$.

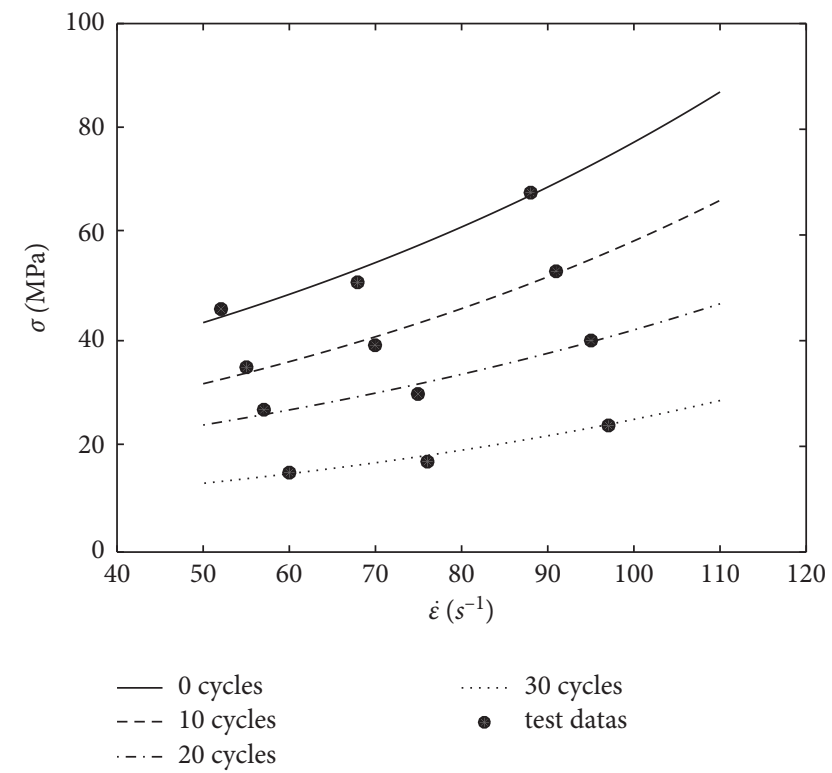

FIGURE 14: Relationship between strain rate and strength of samples with different freeze-thaw cycles under the axial pressure of $5 \mathrm{MPa}$.

TABLE 3: $a$ and $b$ values of strength and strain rate of samples with different freeze-thaw cycles.

\begin{tabular}{lccccc}
\hline & $\begin{array}{c}\text { Freeze-thaw } \\
\text { cycles }\end{array}$ & 0 & 10 & 20 & 30 \\
\hline Axial pressure & $a$ & 22.51 & 9.61 & 5.15 & 1.33 \\
$0 \mathrm{MPa}$ & $b$ & 0.0122 & 0.0162 & 0.0179 & 0.0264 \\
\hline Axial pressure & $a$ & 24.44 & 17.33 & 13.89 & 6.40 \\
$5 \mathrm{MPa}$ & $b$ & 0.0115 & 0.0122 & 0.0110 & 0.0135 \\
\hline
\end{tabular}

Deriving two sides of equation (8) with respect to stress, respectively, we obtain

$$
\frac{d \sigma}{d \varepsilon}=E_{0}\left(1-D_{0}\right) \exp \left[-\left(\frac{\varepsilon}{\beta}\right)^{m}\right]\left[1-\left(\frac{\varepsilon}{\beta}\right)^{m}\right] .
$$

From the condition (2), we obtain

$$
E=E_{0}\left(1-D_{0}\right) \text {. }
$$

Therefore, it can be known that $E_{0}$ in equations (8) and (10) is the dynamic elastic modulus of the intact sample.

According to the condition (3) and equation (8),

$$
\frac{\sigma_{\max }}{E_{0}\left(1-D_{0}\right) \varepsilon_{\max }}=\exp \left[-\left(\frac{\varepsilon_{\max }}{\beta}\right)^{m}\right] \text {. }
$$

Take the logarithm twice on both sides of the equation to get

$$
\ln \left[\ln \frac{E_{0}\left(1-D_{0}\right) \varepsilon_{\max }}{\sigma_{\max }}\right]=m \ln \left(\frac{\varepsilon_{\max }}{\beta}\right) .
$$

According to the condition (4) and equation (8),

$$
\left[1-\left(\frac{\varepsilon}{\beta}\right)^{m}\right]=0
$$

that is,

$$
\frac{1}{m}=\left(\frac{\varepsilon_{\max }}{\beta}\right)^{m} \text {. }
$$

Take the logarithm of both sides to get

$$
\ln \left(\frac{1}{m}\right)=m \ln \left(\frac{\varepsilon_{\max }}{\beta}\right) .
$$

The left sides of equations (12) and (15) are equal to each other, that is,

$$
m=\frac{1}{\ln \left(E_{0}\left(1-D_{0}\right) \varepsilon_{\max } / \sigma_{\max }\right)} .
$$

Substitute equations (16) into (14) and get

$$
\beta=\frac{\varepsilon_{\max }}{(1 / m)^{1 / m}} \text {. }
$$

There are four independent parameters, that are $E_{0}, D_{0}$, $\beta$, and $m$, which can be obtained through the abovementioned experiments. The constitutive relation expression contains the initial total damage parameter $D_{0}$, which can be negative, and the total damage parameter $D_{0}$ contains the coupling result of freeze-thaw damage and axial pressure damage. Obviously, not only the change of $D_{0}$ directly affects the prepeak and postpeak slope of the stress-strain curve but also leads to the change of $\sigma_{\max }$ and $\varepsilon_{\max }$. Therefore, the influence of $D_{0}$ on the stress-strain relationship is complex.

Typical experimental data of two groups of samples with different axial pressures, impact strengths, and degree of freezethaw damage are selected to verify the constitutive model. See Table 4 for parameters. The calculated curve is in good agreement with the experimental data, as shown in Figure 15. 
TABle 4: Parameter values.

\begin{tabular}{|c|c|c|c|c|}
\hline Parameters & $E_{0}$ & $D_{0}$ & $\beta$ & $m$ \\
\hline Freeze-thaw cycle is 0 , axial pressure is $0 \mathrm{MPa}$, launch air pressure is $0.14 \mathrm{MPa}$ & 35.8 & 0 & 0.0048 & 2.8753 \\
\hline Freeze-thaw cycle is 20 , axial pressure is $20 \mathrm{MPa}$, launch air pressure is $0.14 \mathrm{MPa}$ & 11.9 & 0.34 & 0.0092 & 5.2141 \\
\hline
\end{tabular}

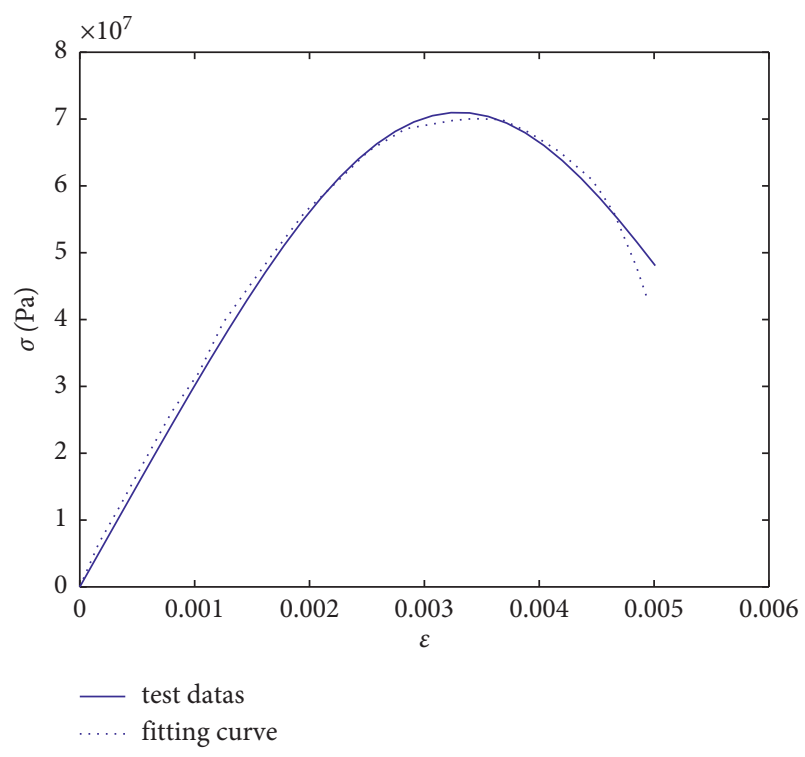

(a)

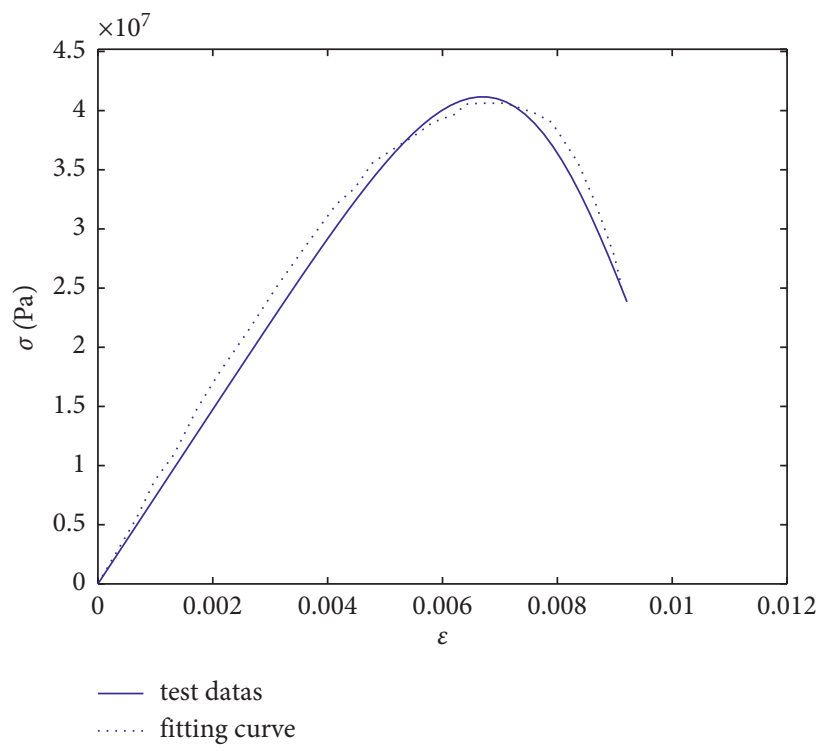

(b)

Figure 15: Calculation curve and experimental data. (a) Freeze-thaw cycle is 0; axial pressure is 0 MPa. (b) Freeze-thaw cycle is 20; axial pressure is $20 \mathrm{MPa}$; launch air pressure is $0.14 \mathrm{MPa}$.

\section{Study on Damage Evolution of Freeze-Thaw Damaged Samples under Dynamic and Static Loading}

According to the rock damage variables $D_{0}, \sigma_{\max }$, and $\varepsilon_{\max }$ of the stress-strain curve obtained from the experiment, a typical comparison chart of the development trend of freezethaw rock damage variables under dynamic and static combined load can be obtained (seen in Figure 16).

The damage evolution curve can reflect the mesomechanical response of rock and is consistent with the macroscopic failure and deformation process of samples. In general, the damage variable increases with the increase of strain. The damage evolution curve is in the shape of " $\mathrm{S}$ "; the curve can be divided into three stages [13]: (1) when the strain is 0 , the initial damage variable of the intact sample is 0 , and the initial stage of the damage variable hardly increases. This is because at the initial elastic stage, the loading stress is far less than the elastic limit of the sample. At this time, there is almost no damage on the sample and only elastic strain is produced. (2) The upper concave of the damage evolution curve corresponds to the plastic deformation stage, the damage variable rises rapidly, the crack expands rapidly, and the sample begins to produce plastic yield. With the increase of strain, the microcracks in the sample continue to expand, and the damage variable keeps increasing. When the crack expansion reaches the critical failure state, that is, the corresponding peak stress, the damage increases at the fastest speed, and unstable crack growth occurs. The convexity inflection point of the damage variable curve corresponds to the peak strength of the sample. The upper convex of the damage evolution curve corresponds to the stage of strain softening, and the slope of the curve gradually decreases, while the crack inside the sample grows more and more rapidly, resulting in the macroscopic fracture of the sample. At this time, the damage variable tends to 1 . With the increase of the peak value of the incident wave, the maximum slope of the damage curve, that is, the slope of the curve at the inflection point increases, indicating that the damage corresponding to the peak strength increases with the increase of the peak value of the incident wave, and the rocks are more fragmented.

The initial damage variable of the sample is not 0 , indicating that the rock has suffered a certain degree of damage degradation before dynamic load. With the increase of the emission pressure, the damage variable approaches to 1 more quickly, and the corresponding peak strain is smaller; the damage accumulation speed of rock is faster, and the plastic property of rock becomes weaker. The damage evolution process of freeze-thaw damaged samples is obviously different from that of intact rocks. Compared with nonfreeze-thaw rocks, the damage variable value of freeze-thaw damage samples at the same 


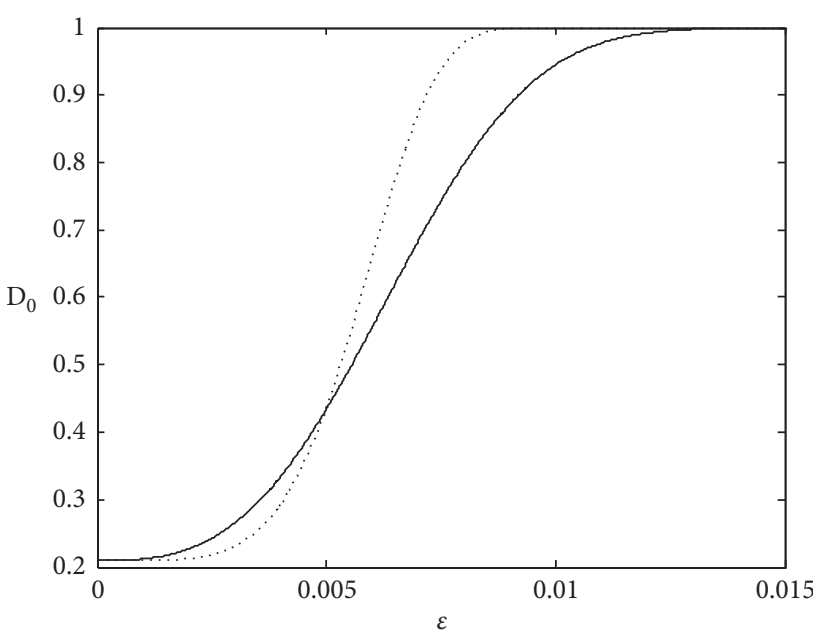

$0.07 \mathrm{MPa}$ $0.14 \mathrm{MPa}$

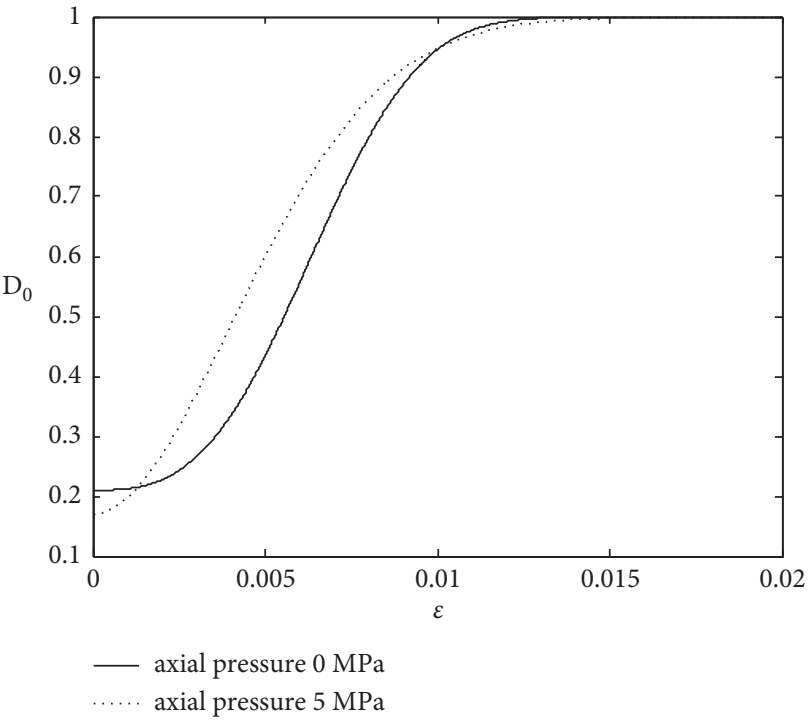

(b)

(a)

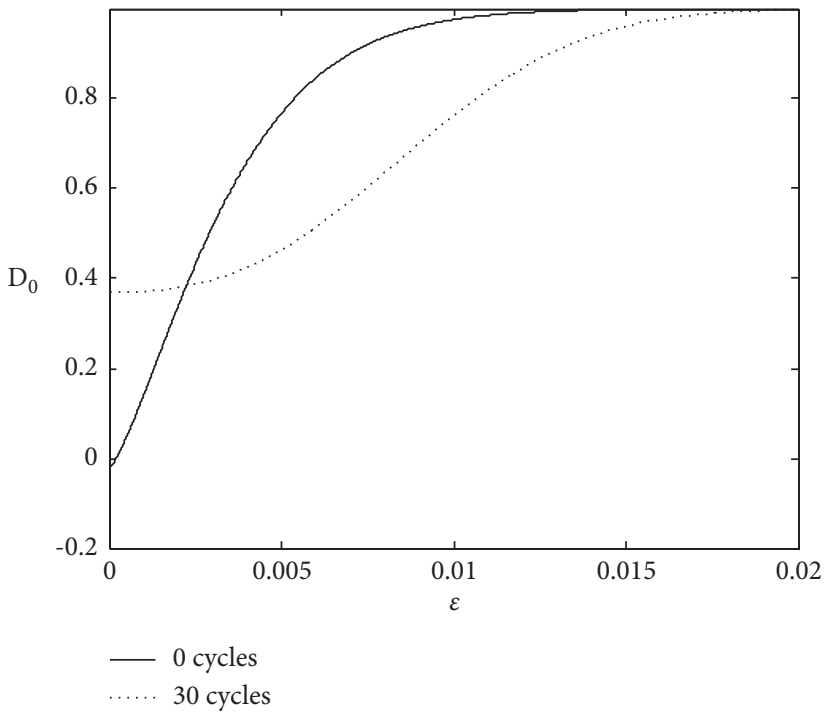

(c)

Figure 16: Typical comparison chart of the development trend of freeze-thaw rock damage variables under dynamic and static combined load. (a) Axial compression $0 \mathrm{MPa}$ and 10 cycles. (b) Air pressure $0.07 \mathrm{MPa}$ and 10 cycles. (c) Axial compression $5 \mathrm{MPa}$ and air pressure $0.07 \mathrm{MPa}$.

strain is generally large (except for the initial development stage of damage), which can reflect the high degree of internal deterioration of the freeze-thaw damaged rocks, and shows the macroscopic reduction of stiffness and strength of freeze-thaw damage rocks. However, when the damage degree is the same, the strain of freeze-thaw damage rock is larger, that is, the damage accumulation speed of freeze-thaw damage rock is slower and the plastic property of the rock is stronger. It also reflects that the maximum slope of damage variable curve of freeze-thaw damaged samples under the same incident wave and the same static load is larger, and crushing degree will be higher. In the process of static and static combined loading, the initial value of rock damage variable may be positive or negative after preaxial compression; after applying axial pressure, the initial horizontal segment of the damage variable curve is very short and soon enters the stage of rapid growth of damage, which indicates the initial linear elastic stage of the sample is short in the process of dynamic and static combined loading, and the internal microcracks of the sample begin to expand at a low dynamic stress level, and then the damage degree of the sample gradually intensifies to the curve inflection point.

\section{Conclusion}

(i) With the increase of freeze-thaw cycles, the rock samples undergo spalling, the weight gradually decreases, the density gradually decreases, the 
compactness of the samples become worse, there are microcracks between the cemented particles, and the compressive strength gradually decreases. After 10 freeze-thaw cycles, the compaction stage of the stress-strain curve increases significantly. Before freeze-thaw, the samples are relatively hard rocks, and after 10 freeze-thaw cycles, they become soft rocks. During 10 to 30 freeze-thaw cycles, all the samples are soft rocks.

(ii) Under static loading, the longitudinal wave velocity of freeze-thaw damaged samples changed significantly compared with that of nonfreeze-thaw samples, according to the formula of damage variable characterized by wave velocity method; the initial total damage parameter $D_{0}$ of the sample under the coupling effect of freeze-thaw and static load can be positive or negative, which reflects the change of the overall density degree inside the sample under the coupling effect of freeze-thaw and static load.

(iii) The degree of freezing-thawing damage, axial pressure, and incident stress wave are mutually coupled, which together affect the dynamic mechanical properties of the sample, making the variation of mechanical parameters such as peak strength and elastic modulus of dynamic and static combined loading of rock damaged by freeze-thaw complex, but also showing certain regularity. The combined action of freeze-thaw damage and axial pressure weakens the strain rate effect of samples; however, when the rock loading forms are the same, the dynamic strength and elastic modulus of freezethaw damaged samples are reduced compared with those without freeze-thaw.

(iv) Combining with strain equivalence principle, the constitutive relation of freeze-thaw damage of red sandstone under dynamic and static combined loading can reflect the influence of coupling damage of axial pressure and freeze-thaw, dynamic impact parameters, and other factors, which is in good agreement with the test results.

\section{Data Availability}

No data were used to support this study.

\section{Conflicts of Interest}

The authors declare that they have no conflicts of interest.

\section{Acknowledgments}

The authors are deeply grateful to the Open Research Fund of Hunan Provincial Key Laboratory of Hydropower Development Key Technology (PKLHD201902), the Fund of National Natural Science Foundation of China (No. 41902298), and the Fund of Natural Science Foundation of Hebei Province (E2018210066) for the continuing financial support of this work.

\section{References}

[1] X. Luo, N. Jiang, X. Fan, N. Mei, and H. Luo, "Effects of freezethaw on the determination and application of parameters of slope rock mass in cold regions," Cold Regions Science and Technology, vol. 110, pp. 32-37, 2015.

[2] Y. Geng-she, Y.-J. Shen, and H.-L. Jia, "Multi-scale study and progress of mechanical properties of damaged rock mass in freeze-thaw environment," Chinese Journal of Rock Mechanics and Engineering, vol. 37, no. 3, pp. 545-563, 2008, in Chinese.

[3] T. Liu, C. Zhang, P. Cao, and K. Zhou, "Freeze-thaw damage evolution of fractured rock mass using nuclear magnetic resonance technology," Cold Regions Science and Technology, vol. 170, Article ID 102951, 2020.

[4] L. Wen, Xi-bing Li, and H. Tang, "Study on the physical and mechanical properties of rocks under freezing-thawing action in variable temperature range and its engineering application," Engineering Mechanics, vol. 34, no. 5, pp. 247-256, 2017, in Chinese.

[5] M. F. İsmailİnce, "A prediction model for uniaxial compressive strength of deteriorated pyroclastic rocks due to freezeethaw cycle," Journal of African Earth Sciences, vol. 120, pp. 134-140, 2016.

[6] M. Fener and İ. İnce, "Effects of the freeze-thaw (F-T) cycle on the andesitic rocks (Sille-Konya/Turkey) used in construction building," Journal of African Earth Sciences, vol. 109, pp. 96-106, 2015.

[7] G. Khanlari and Y. Abdilor, "Influence of wet-dry, freezethaw, and heat-cool cycles on the physical and mechanical properties of Upper Red sandstones in central Iran," Bulletin of Engineering Geology and the Environment, vol. 74, no. 4, pp. 1287-1300, 2015.

[8] J. Park, C.-U. Hyun, and H.-D. Park, "Changes in microstructure and physical properties of rocks caused by artificial freeze-thaw action," Bulletin of Engineering Geology and the Environment, vol. 74, no. 2, pp. 555-565, 2015.

[9] P. Wang, J. Xu, S. Shi, H. Liu, S. Wang, and S. Liu, "Static and dynamic mechanical properties of sedimentary rock after freeze-thaw or thermal shock weathering," Engineering $\mathrm{Ge}$ ology, vol. 210, pp. 148-157, 2016.

[10] K.-p. Zhou, B. Li, J.-l. Li, H.-w. Deng, F. Bin, and J.-l. Li, "Microscopic damage and dynamic mechanical properties of rock under freeze-thaw environment," Transactions of Nonferrous Metals Society of China, vol. 25, no. 4, pp. 1254-1261, 2015.

[11] W. Lei, L. Xi-bing, W. Qiu-hong, W. Lei, and S Wei, "Study on dynamic load strength of granite-porphyry under freeze-thaw cycle [J]," Chinese Journal of Rock Mechanics and Engineering, vol. 34, no. 7, pp. 1297-1306, 2015, in Chinese.

[12] D. Ma, H. Duan, Q. Zhang et al., "A numerical gas fracturing model of coupled thermal, flowing and mechanical effects," Computers, Materials \& Continua, vol. 65, no. 3, pp. 21232141, 2020.

[13] H. Zhang, X. Meng, C. Peng, G. S. Yang, and W. J. Ye, "Rock damage constitutive model based on residual intensity characteristics under freeze-thaw and load," Journal of China Coal Society, vol. 44, no. 11, pp. 3404-3411, 2019, in Chinese.

[14] M. Xu, A. Jiang, and Y. Zhang, "A coupling damage model under freeze-thaw cycles and loading based on Hoek-Brown criterion and its algorithm research," Journal of Basic Science and Engineering, vol. 29, no. 3, pp. 702-717, 2021, in Chinese.

[15] Y. Lu, X. Li, and A. Chan, "Damage constitutive model of single flaw sandstone under freeze-thaw and load," Cold Regions Science and Technology, vol. 159, pp. 20-28, 2019. 
[16] Yangtze River Scientific Research Institute and Changjiang Water Resources Commission, Specifications for Rock Tests in Water Conservancy and Hydroelectric engineering(SL2642001), China Water Power Press, Beijing, China, 2001.

[17] Chinese Society for Rock Mechanics, Group standards, Beijing, China, T/CSRME001-2019 Test code for dynamic characteristics of rock, 2019.

[18] C.-B. Yan, "Blasting cumulative damage effects of underground engineering rock mass based on sonic wave measurement," Journal of Central South University of Technology, vol. 14, no. 2, pp. 230-235, 2007.

[19] J. Zhu, T. Zhai, Z. Liao, S. Yang, X. Liu, and T. Zhou, "Lowamplitude wave propagation and attenuation through damaged rock and a classification scheme for rock fracturing degree," Rock Mechanics and Rock Engineering, vol. 53, no. 9, pp. 3983-4000, 2020.

[20] M. Mutlutürk, R. Altindag, and G. Türk, “A decay function model for the integrity loss of rock when subjected to recurrent cycles of freezing-thawing and heating-cooling," International Journal of Rock Mechanics and Mining Sciences, vol. 41, no. 2, pp. 237-244, 2004.

[21] Z. Y. Liu, Y. L. Hu, and Y. Chen, "Ultrasonic P-wave attenuation in dry and saturated rocks under uniaxial compression[J]," ACTA Geophysica Sinica, vol. 27, no. 4, pp. 349-359, 1984.

[22] X. Li, F. Gong, and J. Zhao, "Test study of impact failure of rock subjected to one-dimensional coupled static and dynamic loads," Yanshilixue Yu Gongcheng Xuebao/Chinese Journal of Rock Mechanics and Engineering, vol. 29, no. 2, pp. 251-260, 2010, in Chinese.

[23] F.-Q. Gong, X-B. Li, X-L. Liu, and Z. Jian, "Experimental study on dynamic characteristics of sandstone under onedimensional dynamic and static combination loading," Chinese Journal of Rock Mechanics and Engineering, vol. 29, no. 10, pp. 2076-2085, 2010, in Chinese.

[24] J. Lematire, "How to use damage mechanics," Nuclear Eang.ङDesign, vol. 80, no. 2, pp. 233-245, 1984.

[25] Q. Zhang, G. Yang, and J. Ren, "New study of damage variable and constitutive equation of rock," Chinese Journal of Rock Mechanics and Engineering, vol. 22, no. 1, pp. 30-34, 2003, in Chinese.

[26] C. A. Tang, H. Liu, P. K. K. Lee, Y. Tsui, and L. G. Tham, "Numerical studies of the influence of microstructure on rock failure in uniaxial compression - Part I: effect of heterogeneity," International Journal of Rock Mechanics and Mining Sciences, vol. 37, no. 4, pp. 555-569, 2000. 